\title{
Влияние образования силицидов на удельное сопротивление кремния
}

\author{
(С) Б.Е. Умирзаков, Д.А. Ташмухамедова, Г.Х. Аллаярова, Ж.Ш. Содикжанов \\ Ташкентский государственный технический университет, Ташкент, Узбекистан \\ E-mail: ftmet@mail.ru
}

Поступило в Редакцию 21 декабря 2018 г.

В окончательной редакции 21 декабря 2018 г.

Принято к публикации 16 января 2019 г.

\begin{abstract}
Впервые исследовано влияние образования тонких пленок силицидов никеля на миграцию собственных примесей $p$-типа кремния. Установлен существенный рост (до 3-4 раз) объемного сопротивления $\rho_{v}$ монокристалла $\mathrm{Si}$ при формировании на его поверхности пленки $\mathrm{NiSi}_{2}$ толщиной $\theta \geq 50-100 \AA$, что объясняется миграцией атомов бора в сторону силицидной пленки. Оценочная толщина слоя $\mathrm{Si}$, при которой происходит интенсивная миграция бора, составляет 800-1000 А.
\end{abstract}

DOI: 10.21883/PJTF.2019.07.47539.17650

В настоящее время хорошо изучены состав, структура и свойства наноразмерных слоев, созданных на поверхности и в приповерхностных слоях монокристаллов кремния [1-6]. Между наноразмерным слоем и подложкой формируется переходный слой. Формирование пленки и переходного слоя во многих случаях приводит к миграции примесных атомов подложки, а следовательно, и к изменению ее электронных, оптических и магнитных свойств. Например, при контакте пленка-подложка на границе раздела в зависимости от их работы выхода и типа проводимости происходит искривление зон. В частности, в полупроводнике $n$-типа в области искривления зон число донорных электронов либо уменьшается, либо увеличивается. Уменьшение приводит к увеличению удельного сопротивления в этой области подложки. Дальнейшие исследования показали, что при контакте двух материалов вблизи границы раздела наряду с искривлением зон может происходить перераспределение примесных атомов. Для выяснения этого в работе [7] в пластины монокристаллического $\mathrm{Si}$ были специально введены примеси S, Tl, Ge, P и на поверхность этого образца осаждены атомы Pt. После прогрева при $T=350^{\circ} \mathrm{C}$ на поверхности $\mathrm{Si}$ образовалась пленка моносилицида Pt. Оже-профили, полученные при послойном травлении образца ионами $\mathrm{Ar}^{+}$, показали, что в процессе формирования силицида платины легирующие примеси перемещались либо в глубь кремния, либо в слой силицида. Обнаружено, что если сумма абсолютных величин разностей электроотрицательностей примеси и силицидообразующих элементов равна приблизительно 0.4, то атомы примеси смещаются в глубь кремния. При большем значении этой суммы примесь мигрирует в сторону силицида. Перемещение примесных атомов $\mathrm{O}$ и $\mathrm{K}$ наблюдается также при образовании тонких слоев $\mathrm{BaSi}_{2}$ на поверхности $\mathrm{Si}$ [8]. Однако до настоящего времени не исследовалось влияние образования силицидных нанопленок на миграцию собственных ( $p$ - или $n$-типа) примесей и физические свойства кремния. Результаты подобных исследований очень важны для создания слоистых структур, применяемых в приборах микро-, опто- и наноэлектроники, в частности для повышения эффективности солнечных элементов за счет увеличения стабильности их параметров при эксплуатации. В работах $[9,10]$ показано, что коэффициент поглощения света кремния $n$-типа в

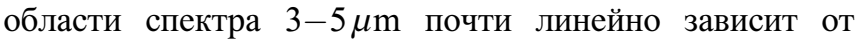
удельного сопротивления.

Целью настоящей работы является изучение изменения профилей распределения примесных атомов бора по глубине кремния при формировании на его поверхности силицида никеля и их влияния на объемное удельное сопротивление $\mathrm{Si}$.

В качестве объектов исследования использовались пластины монокристаллического $\mathrm{Si}$ (111) p-типа (КДБ-10) с толщиной $\sim 0.5 \mu \mathrm{m}$. Пленка $\mathrm{NiSi}_{2} / \mathrm{Si}(111)$ толщиной $\theta=50-150 \AA$ получена путем имплантации ионов $\mathrm{Ni}^{+}$в $\mathrm{Si}$ в сочетании с отжигом, а пленки толщиной $\theta=100-500 \AA-$ твердофазным осаждением атомов Ni в Si с последующим прогревом. Перед получением пленок $\mathrm{NiSi}_{2}$ поверхность $\mathrm{Si}$ (111) очищалась прогревом до $T=1300-1500 \mathrm{~K}$ в сочетании с распылением поверхности ионами $\mathrm{Ar}^{+}$. Для исследования были подготовлены шесть одинаковых пластин кремния. На поверхности пяти образцов сразу после очистки выращены пленки $\mathrm{NiSi}_{2} / \mathrm{Si}$ (111) разной толщины и измерены объемные и поверхностные удельные сопротивления системы. Для более точной оценки миграции бора в шестой образец $\mathrm{Si}$ после очистки дополнительно введены ионы бора с энергией $E_{0}=40 \mathrm{keV}$ при дозе $D=10^{15} \mathrm{~cm}^{-2}$. После прогрева при $T=700-800 \mathrm{~K}$ этой системы концентрация В в приповерхностной области $\mathrm{Si}$ толщиной 500-600 $\AA$ составляла $\sim 0.5-1$ at.\%. Затем на поверхности этого образца выращена пленка $\mathrm{NiSi}_{2}$. Основные исследования по определению миграции примесных атомов в $\mathrm{Si}$ в процессе образования $\mathrm{NiSi}_{2}$ проводились на образце № 6. Ионная имплан- 
Таблица 1. Значения $\rho_{v}(\Omega \cdot \mathrm{cm})$ для чистого и ионно-имплантированного кремния (образец № 2)

\begin{tabular}{c|c|c}
\hline \multirow{2}{*}{$\mathrm{Si}(111), p$-тип } & \multicolumn{2}{|c}{$\mathrm{Si}$, имплантированный ионами $\mathrm{Ni}^{+}$} \\
\cline { 2 - 3 } & до прогрева & после прогрева \\
\hline $9-10$ & $10-11$ & $13-14$
\end{tabular}

тация, твердофазное осаждение и термический отжиг осуществлялись при вакууме не хуже чем $10^{-6} \mathrm{~Pa}$, а исследования состава и структуры - при вакууме $10^{-7} \mathrm{~Pa}$. Элементный и химический состав поверхности определялся методом оже-электронной спектроскопии (ОЭС), а профили распределения примесных атомов по глубине - методом ОЭС в сочетании с послойным травлением поверхности ионами $\mathrm{Ar}^{+}$с $E_{0}=2 \mathrm{keV}$ под углом 5-10 ${ }^{\circ}$ относительно поверхности образца. Все исследования проводились при комнатной температуре.

В табл. 1 приведены значения объемного удельного сопротивления $\rho_{v}$ для $\mathrm{Si}$, имплантированного ионами $\mathrm{Ni}^{+}$с вариацией энергии $E_{0}=10,5$ и $1 \mathrm{keV}$ при дозе насыщения $D=D_{\text {sat }}=8 \cdot 10^{16} \mathrm{~cm}^{-2}$, до и после прогрева при $T=1000 \mathrm{~K}$. Видно, что после ионной имплантации значение $\rho_{v}$ заметно не меняется, а после прогрева существенно увеличивается. Для выяснения этого эффекта использовался образец № 6, имплантированный ионами $\mathrm{Ni}^{+}$с $E_{0}=10,5$ и $1 \mathrm{keV}$ при дозе насыщения.

На рисунке приведены профили распределения атомов $\mathrm{Ni}, \mathrm{O}$ и В по глубине системы, полученные до и после прогрева при $T=1000 \mathrm{~K}$. Отметим, что до прогрева приповерхностные слои $\mathrm{Si}$ полностью аморфизируются и в этих слоях содержатся соединения типа $\mathrm{Ni}_{x} \mathrm{Si}_{y}$ и свободные атомы $\mathrm{Ni}$ и Si. После прогрева формируется монокристаллическая пленка $\mathrm{NiSi}_{2}$ с резкой границей. Из рисунка, $a$ видно, что в сильно легированной области кремния $(d \leq 100-120 \AA)$ практически не обнаруживаются атомы кислорода и бора. Атомы кислорода в основном накапливаются в переходном слое границы ионно-легированный слой/кремний. Концентрация бора немного увеличивается вблизи этой границы и при $d>200-225 \AA$ практически не меняется и сохраняется на уровне 0.5-0.6 at.\%, следовательно, не происходит существенного изменения $\rho_{v}$ кремния. После прогрева этой системы при $T=1000 \mathrm{~K}$ формируется эпитаксиальная пленка $\mathrm{NiSi}_{2}$ с толщиной $\theta=130-150 \AA$, и ширина переходного слоя резко уменьшается (см. рисунок, $b$ ). В переходном слое общая концентрация О практически не меняется (площадь под кривой не изменяется), однако его концентрация в максимуме увеличивается в 1.5 раза. Что касается атомов В, то его концентрация в пленке $\mathrm{NiSi}_{2}$ уменьшается до нуля (в пределах чувствительности ОЭС). В переходном слое концентрация В существенно увеличивается, проходит через максимум при $d=200-225 \AA$, а затем уменьшается и при $d>250 \AA$ не превышает $0.2-0.3$ at.\%. Анализируя
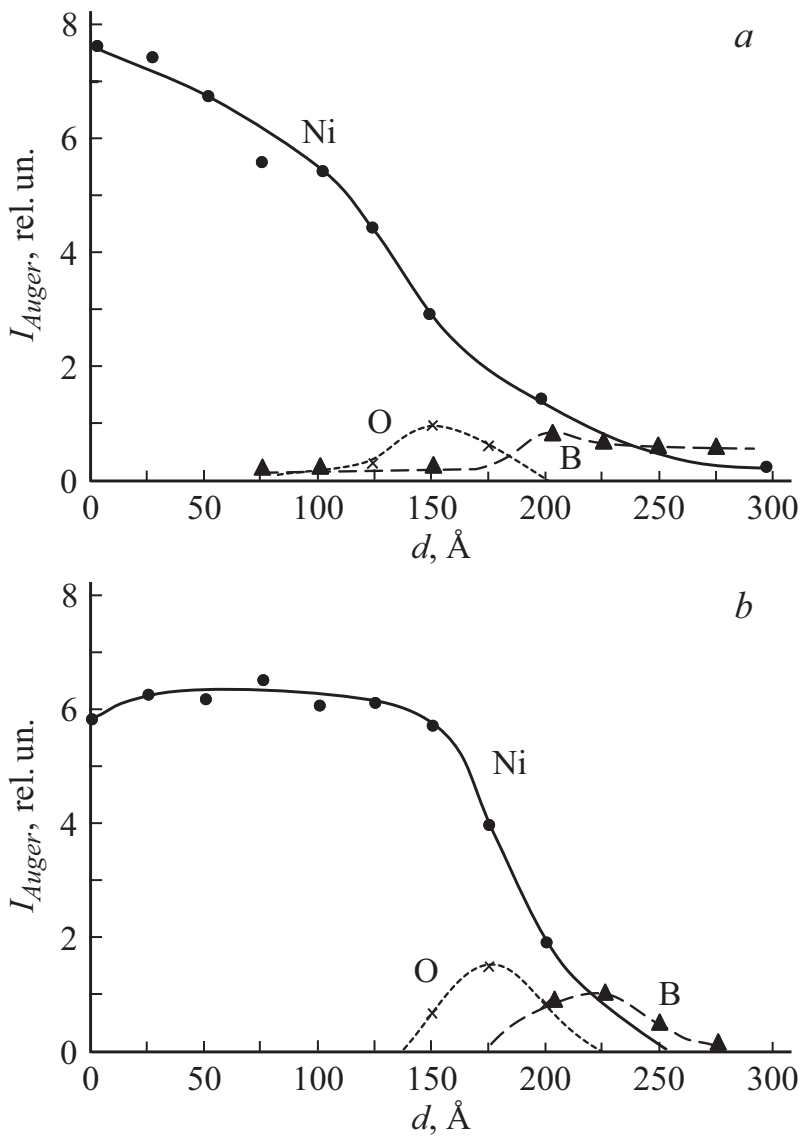

Профили распределения атомов Ni, О и В по глубине $\mathrm{Si}$ (111), последовательно имплантированного ионами $\mathrm{Ni}^{+}$с $E_{0}=10,5$ и $1 \mathrm{keV}$ при $D=8 \cdot 10^{16} \mathrm{~cm}^{-2} \cdot a-$ до прогрева, $b-$ после прогрева при $T=1000 \mathrm{~K}$ в течение $30 \mathrm{~min}$.

эти данные, можно полагать, что существенная миграция примесных атомов на границе пленка-подложка в основном происходит после кристаллизации разупорядоченных слоев и формирования эпитаксиальной системы силицид-кремний со сравнительно резкой границей. Повидимому, миграция В в сторону силицида приводит к уменьшению концентрации В и увеличению $\rho_{v}$ кремния в слоях ниже переходных.

В табл. 2 приведены значения $\rho_{v}$ и $\rho_{s}$ для образцов системы $\mathrm{NiSi}_{2} / \mathrm{Si}(111)$ с разной толщиной $\mathrm{NiSi}_{2}$, полученных методами ионной имплантации и твердофазного осаждения в сочетании с отжигом $\left(\rho_{s}-\right.$ поверхностное сопротивление).

Из табл. 2 видно, что удельное сопротивление поверхностных слоев, т.е. пленки $\mathrm{NiSi}_{2}$, составляет $\sim 60 \mu \Omega \cdot \mathrm{cm}$, что хорошо согласуется с литературными данными [11]. Объемное удельное сопротивление $\rho_{v}$ в случае образца № 1 (толщина пленки $\mathrm{NiSi}_{2} \sim 50 \AA$ ) практически не меняется. По-видимому, при малых толщинах пленки еще не происходит заметной миграции бора. Существенный рост $\rho_{v}$ для пленок, полученных разными методами, происходит начиная с $\theta=150-200 \AA$ (образцы № 2 и 3). Увеличение $\rho_{v}$ системы наблюдается 
Таблица 2. Значения $\rho_{v}$ и $\rho_{s}$ системы $\mathrm{NiSi}_{2} / \mathrm{Si}(111)$

\begin{tabular}{|c|c|c|c|c|c|}
\hline $\begin{array}{c}\text { Номер } \\
\text { образца }\end{array}$ & $\begin{array}{c}\text { Толщина } \\
\text { пленки } \\
\mathrm{NiSi}_{2}(\theta), \AA\end{array}$ & $\begin{array}{c}\text { Метод } \\
\text { получения }\end{array}$ & $\begin{array}{c}T^{*}, \\
\mathrm{~K}\end{array}$ & $\begin{array}{c}\rho_{v}, \\
\Omega \cdot \mathrm{cm}\end{array}$ & $\begin{array}{c}\rho_{s} \cdot 10^{-6} \\
\Omega \cdot \mathrm{cm}\end{array}$ \\
\hline 1 & 50 & $\begin{array}{c}\text { Ионная } \\
\text { имплантация }\end{array}$ & 900 & $9-10$ & - \\
\hline 2 & 150 & То же & 1000 & $13-14$ & 60 \\
\hline 3 & 150 & $\begin{array}{c}\text { Твердофазная } \\
\text { эпитаксия }\end{array}$ & 900 & $14-15$ & 60 \\
\hline 4 & 400 & То же & 1000 & $35-40$ & 60 \\
\hline 5 & $500-550$ & $\gg$ & 1000 & $35-40$ & 50 \\
\hline
\end{tabular}

* Прогрев при каждой $T$ проводился в течение $30 \mathrm{~min}$.

до $\theta=400-500 \AA$, а затем с ростом толщины пленки силицида заметно не меняется.

Наши дальнейшие исследования были направлены на оценку толщины слоя $\mathrm{Si}$, при которой происходит интенсивная миграция атомов В в сторону силицида. Для этого поверхностные слои образца № 4 вытравливались ионами $\mathrm{Ar}^{+}$до толщины $1000 \AA$, а образца № 5 до толщины $1500 \AA$ и в течение $30 \mathrm{~min}$ нагревались при $T=1000 \mathrm{~K}$, а затем измерялись $\rho_{v}$. В случае образца № 4 значение $\rho_{v}=10-12 \Omega \cdot \mathrm{cm}$, а в случае образца № $5 \rho_{v}=9-10 \Omega \cdot \mathrm{cm}$, что практически совпадает с $\rho_{v}$ чистого $\mathrm{Si}$. Исходя из этого можно полагать, что толщина слоя, при которой происходит миграция В, составляет $800-1000 \AA \AA$.

Таким образом, результаты экспериментальных данных показывают, что формирование силицидной пленки на поверхности $\mathrm{Si}$ приводит к миграции атомов собственной примеси $p$-типа в сторону силицида, следовательно, объемное удельное сопротивление $\mathrm{Si}$ при комнатной температуре увеличивается в $3-4$ раза. Толщина обедненного слоя, при которой наблюдается увеличение $\rho_{v}$, составляет $\sim 800-1000 \AA$.

\section{Список литературы}

[1] Cho W.S., Kim J.Y., Park N.G., Lyo I.W., Jeong K., Kim S.S., Choi D.S., Whang S.N., Chae K.H. // Surf. Sci. 2000. V. 453. N 1-3. P. L309-L314. https://doi.org/10.1016/S0039- 6028(00)00344-7

[2] Гомоюнова М.В., Пронин И.И., Малыгин Д.Е., Галль Н.Р., Вялых Д.В., Молодцов С.Л. // ФТТ. 2005. Т. 47. В. 10. C. 1901-1906. http://journals.ioffe.ru/articles/4014

[3] Watanabe M., Iketani Y., Asada M. // Jpn. J. Appl. Phys. 2000. V. 39. N 10A. Pt 2. P. L964-L967. http://iopscience.iop.org/article/10.1143/JJAP.39.L964

[4] Сутурин С.М., Банщиков А.Г., Соколов Н.С., Тягинов С.Э., Векслер М.И. // ФТП. 2008. Т. 42. В. 11. С. 1333-1338. http://journals.ioffe.ru/articles/6694

[5] Мурадкабилов Д.М., Ташмухамедова Д.А., Умирзаков Б.Е. // Поверхность. Рентгеновские, синхротронные и нейтронные исследования. 2013. № 10. С. 58-62.
[6] Умирзаков Б.Е., Ташмухамедова Д.А., Рузибаева М.К., Ташатов А.К., Донаев С.Б., Мавлянов Б.Б. // ЖТФ. 2013. T. 83. B. 9. C. 146-149. http://journals.ioffe.ru/articles/11015

[7] Vasiliev S.V., Gerasimenko N.N., Altukhov A.A., Ivanov V.V. // Phys. Status Solidi A. 1986. V. 96. N 2. P. K163-K167. https://onlinelibrary.wiley.com/doi/10.1002/pssa.2210960253

[8] Умирзаков Б.Е., Ниматов С.Ж., Болтаев Х.Х. // Поверхность. Рентгеновские, синхротронные и нейтронные исследования. 2014. № 9. С. 87-90.

[9] Sze S.M., Irvin J.C. // Solid-State Electron. 1968. V. 11. N 6. P. 599-602. https://doi.org/10.1016/0038-1101(68)90012-9

[10] Несмелова И.М., Астабьев Н.И., Кулакова Н.А. // Опт. журн. 2012. Т. 79. № 3. С. 87-90. http://www.opticjourn.ru/ download/private/0-1203-87.pdf

[11] Самсонов Т.В., Дворина Л.А., Рудь Б.М. Силициды. М.: Металлургия, 1979. 372 с. 